\title{
ESTIMACIÓN DE LA DURACIÓN DEL CICLO CELULAR Y ESTANDARIZA- CIÓN DEL PROTOCOLO CITOGENÉTICO EN Guadua angustifolia Kunth var. angustifolia (BAMBUSOIDEAE, POACEAE)
}

\author{
ESTIMATION OF CELL CYCLE DURATION AND STANDARDIZATION OF CYTOGENETIC \\ PROTOCOL Guadua angustifolia Kunth var. angustifolia (BAMBUSOIDEAE, POACEAE).
}

Jenny Carolina Valencia Rincón ${ }^{1}$ y Nohra Rodríguez Castillo ${ }^{1}$

${ }^{1}$ Programa de Biologia Universidad del Quindio. jennycarolina1988@gmail.com, nohrarodriguez@gmail.com

\author{
Recibido: Julio 19 de 2012 \\ Aceptado: Octubre 10 de 2012 \\ *Correspondencia del autor . Programa de Biologia Universidad del Quindio, Av. Bolivar calle 12 norte \\ Armenia Quindío Colombia. e-mail: jennycarolina1988@gmail.com
}

\begin{abstract}
RESUMEN
Guadua angustifolia posee importancia económica y ecológica tanto en las regiones donde es nativa como en aquellas donde ha sido introducida razón por la cual se han desarrollado múltiples trabajos de investigación encaminados a determinar su diversidad genética y sus propiedades físico-mecánicas, entre otros, los cuales están dirigidos a programas de conservación, propagación y mejoramiento genético. En el presente trabajo se evaluó el ciclo celular y se estandarizó la técnica citogenética a partir de tejido meristemático radicular. Se determinó la hora mitótica realizando colecta de ápices cada hora durante 24 horas. Por otro lado, se aplicaron técnicas de: Pre-tratamiento, fijación, hidrólisis, tinción y montaje, para la acumulación de células metafásicas a fin de lograr la estandarización del protocolo para estudios citogenéticos. Los resultados indicaron que esta especie posee un ciclo celular corto en el tejido meristemático que no supera las cinco horas y un comportamiento bimodal en cuanto a su actividad mitótica. La estandarización del protocolo para la obtención de células metáfasicas se logró con un pretratamiento con colchicina al 1\%, fijación durante 24 horas con Carnoy, hidrólisis doble con $\mathrm{HCl}$ al $2 \mathrm{~N}$ y un coctel enzimático de celulasa, macerozima y pectinasa, tinción con orceína acética o DAPI, según fuera el caso y montaje del tejido mediante las técnicas de squash o extendido.
\end{abstract}

Palabras clave: Guadua angustifolia, Ciclo celular, Citogenética vegetal, meristemo radicular. 


\begin{abstract}
Guadua angustifolia has economic and ecological importance both in its native and in those where it has been introduced which is why they have developed multiple research aimed to determine the genetic diversity and its physical and mechanical properties, among others, which programs are aimed at conservation, propagation and breeding. The present study evaluated the cell cycle and cytogenetic technique was standardized from root meristem. Mitotic time was determined by performing collection of apices each hour for 24 hours. Furthermore, techniques were applied: Also, pre-treatment, fixation, hydrolysis, staining and mounting techniques were implemented in order to accumulate metaphase cells to achieve the standardization of the protocol for cytogenetic studies. The results indicated that this species has a short cell cycle in meristematic tissue which does not exceed five hours and a bimodal behavior in their mitotic activity. The standardization of the protocol for obtaining metaphase cells was achieved by pretreatment with colchicine $1 \%$ fixation for 24 hours with Carnoy, double hydrolysis with $2 \mathrm{~N} \mathrm{HCl}$ and a cocktail enzyme cellulase and pectinase macerozyme, staining with acetic orcein or DAPI, as the case and tissue assembly through the techniques of squash or extension.
\end{abstract}

Keywords: Guadua angustifolia, Cell Cycle, plant Cytogenetic, meristematic root

\section{INTRODUCCIÓN}

La especie Guadua angustifolia es uno de los bambúes americanos con importancia a nivel mundial (1); está distribuido a través de Colombia, Ecuador y Venezuela (2); ha sido introducido en varios países de Centro América, el Caribe y Asia. Se encuentra naturalmente en los bosques muy húmedo subtropical (bmh-ST), bosque húmedo subtropical (bh-ST), bosque seco tropical (bs-T) y bosque muy húmedo montano bajo (bmh-MB). Esta presente tanto en la región tropical como en la subtropical, pero se encuentra en mayores áreas en los bosques húmedos y muy húmedos concentrándose en las laderas de montaña y en las riveras de los ríos (3). En Colombia se encuentra distribuida en la región central de los andes (cordilleras central y occidental) generalmente entre los 1.000 y $1.500 \mathrm{~m}$ de altitud, en esta zona se conserva, un área de aproximadamente 17.000 hectáreas entre guaduales naturales y cultivados (3-5).

La guadua es una especie multipropósito que proporciona servicios ambientales y bienes al hombre para sus necesidades. Desde el punto de vista ambiental la guadua posee la capacidad de regulación y control de las fuentes hídricas; esto relacionado con la estructura morfológica de su culmo, que le permite la retención de agua además de su sistema radicular entrecruzado que amarra los suelos evitando su erosión $(6,7)$. Además por ser una planta de rápido crecimiento y de tipo leñoso, tiene la capacidad de fijar cincuenta toneladas métricas de $\mathrm{CO}_{2}$ ha/año (7). En cuanto a los usos dados por el hombre a la especie están: la utilización en la construcción y reparación de viviendas, usos domésticos, artesa- nales y para la industria de la pulpa, laminados y todo lo relacionado con la cadena productiva que gira en torno a esta especie.

A pesar de la importancia económica y ecológica de Guadua angustifolia, la información citológica de la especie es poca; hasta el momento no se encuentra reporte alguno sobre la duración del ciclo celular, el número cromosómico, o el cariotipo; lo que es una limitante para la resolución de problemas taxonómicos y el uso sostenible de la especie, dado que el cariotipo permite la caracterización de especies, poblaciones, individuos, biotipos o razas (8).

Consecuentemente, los objetivos de la presente investigación consistieron en: 1) Determinar la hora y el índice mitótico para Guadua angustifolia biotipo macana. 2) Estandarizar el protocolo citogenético para la obtención de células metafásicas adecuadas para estudios de citogenética.

\section{MATERIALES Y MÉTODOS}

\section{Colecta de material vegetal}

Se colectaron 60 chusquínes (plántulas originadas por reproducción vegetativa) y 60 riendas laterales (esquejes) de Guadua angustifolia var. angustifolia biotipo macana en la Reserva Natural "La Montaña del Ocaso" ubicada en el municipio de Quimbaya; se transportaron al invernadero del programa de Biología en la UQ, donde se sembraron en vermiculita suplementada con medio M\&S liquido, realizando riegos con agua de grifo periódicamente. 


\section{Fase de Laboratorio}

La determinación taxonómica de la especie se llevó a cabo en el laboratorio de Biotecnología Vegetal del CIBUQ de la Universidad del Quindío, y en colaboración con el laboratorio de Citogenética Vegetal del Centro Nacional de Investigaciones de Café (CENICAFÉ), se desarrollo la estandarización del protocolo.

\section{Ciclo celular e índice mitótico}

Se aislaron muestras de ápices radiculares en intervalos de una hora (tres ápices radiculares cada hora), durante 24 horas, éstas se fijaron en Carnoy (Etanol absoluto + Ácido acético glacial en proporción 3:1) durante 24 horas a $3^{\circ} \mathrm{C}$.

Según lo sugerido por Talledo y Escobar (9), una vez fijados, se realizo una hidrólisis acida con $\mathrm{HCl} 1 \mathrm{~N}$ a $60^{\circ} \mathrm{C}$ por 5 minutos y posteriormente se maceraron con cuchilla en aceto-orceína durante 10 minutos; a continuación se realizó el squash o aplastamiento, golpeando la muestra con una varilla de goma, lo que permitió obtener una sola capa de tejido meristemático.

Las muestras procesadas cada hora se evaluaron al microscopio en el campo visual de 40X, realizando conteo celular e identificando la fase del ciclo celular en que se encontraba (interfase, profase, metafase, anafase, telofase) con un mínimo de 1200 células por montaje (cada hora), para la determinación del índice de fases parciales, Índices de fases totales, índice mitótico y duración del ciclo celular.

Una vez establecida la duración del ciclo celular, se determinó la hora del día con mayor índice mitótico (IM $m$ ), es decir, la hora en la cual se dividen más intensamente las células meristemáticas del ápice radicular, como la hora óptima para la colecta de ápices.

La duración del ciclo celular del tejido meristemático y hora mitótica para la especie, se determinó mediante la metodología sugerida por Talledo y Escobar (9), realizando tres repeticiones del ciclo durante 24 horas en diferentes días; con el fin de minimizar el sesgo que se puede presentar al realizar el análisis solo una vez, ya que, las condiciones ambientales en las que se encuentra la planta influye en las fluctuaciones presentadas en las poblaciones celulares. Los ápices radiculares se colectan cada hora durante el periodo de 24 horas. Posteriormente se procesaron las raíces y se realizaron los registros fotográficos con los cuales se calculó el índice de fases en porcentaje tanto parcial por hora como total; posteriormente se realizó el cálculo del IM $m$ en porcentaje parcial y total, haciendo uso de las siguientes formulas, con lo que se determinó la hora mitótica.

Cálculo de índices de fases

$$
\begin{gathered}
I F p \%=\frac{\# \text { celulas de cada fase }}{\# \text { total de de celulas }} \times 100 \\
I F t(\%)=\frac{I F(\%) \text { parciales de cada fase }}{\# \text { total de horas }} \times 100
\end{gathered}
$$

Cálculo del índice mitótico

$$
\begin{gathered}
I M_{p}(\%)=I F_{P}+I F_{m}+I F_{a}+I F_{t} \\
I M_{T}(\%)=I F_{P}+I F_{m}+I F_{a}+I F_{t(I F \text { totales })}
\end{gathered}
$$

$I F_{p}=$ índice de fases parciales

$I M_{p}^{p}=$ índice mitótico parcial

$I F_{T}^{p}=$ índice de fases total

$I M_{T}=$ índice mitótico total

\section{Obtención de cromosomas en metafase}

La estandarización del protocolo para la obtención de cromosomas en metafase se realizó a partir de las técnicas descritas en citogenética vegetal (10-13). Para el proceso se consideraron cinco fases: Pretratamiento, fijación, hidrólisis, coloración y montaje, sobre las cuales se trabajó para generar una metodología adecuada para esta especie.

Pretratamiento: Se emplearon dos de los agentes inhibidores mitóticos propuestos por Jahier (13), los cuales fueron colchicina $1 \%$ por 1 y 2 horas y baja temperatura $\left(0^{\circ} \mathrm{C}\right)$ por 12 y 24 horas. Se definió el mejor pretratamiento de forma cualitativa, por observación de los cromosomas en el campo visual de 100X, teniendo en cuenta que se observaran células en metafase con posibilidad de conteo y cromosomas dispersos.

Fijación: Se empleó Carnoy fresco (3 etanol al 96\%: 1 ácido acético glacial), de acuerdo con lo recomendado por Sharma y Sharma (11). Evaluando diferentes tiempos de fijación con Carnoy (12, 24, 36 y 48 horas a $3^{\circ} \mathrm{C}$ ), para determinar cualitativamente cual fue el de mejor tiempo por medio de la observación de las láminas.

Hidrólisis: Se evaluó la hidrólisis ácida, enzimática y la combinación de ambas; en el primer caso de utilizó $\mathrm{HCl}$ al $1 \mathrm{~N}, 2 \mathrm{~N}$ y $3 \mathrm{~N}$ a $60^{\circ} \mathrm{C}$ por 10,15 y 20 minutos, en el segundo caso se realizaron cocteles enzimáticos de celulasa (1.8 y 3.6\%) Yakuh Honsha ${ }^{\circledR}$, macerozima $(0.2$ y $0.4 \%$ ) Yakuh Honsha ${ }^{\circledR}$ y pectinasa (3 y $6 \%$ ) Sigma ${ }^{\circledR}$, 
a $37^{\circ} \mathrm{C}$ y la doble hidrólisis se realizó con $\mathrm{HCl}$ al $2 \mathrm{~N}$ y coctel enzimático en ambas concentraciones por 1, 1.5 y 2 horas, en cámara húmeda.

Se evaluó su efectividad por la calidad de los cromosomas, utilizando la microfotografía como evidencia y justificación de la elección de alguno de los métodos.

Tinción, montaje y observación: Para la tinción de los cromosomas se utilizaron dos tipos de sustancias; en el primer caso se usó aceto-orceína como lo sugiere García (14), tomando secciones de tejido de aproximadamente $3 \mathrm{~mm}$ de longitud que se colocaron sobre el portaobjetos con $30 \mu \mathrm{l}$ de aceto-orceína durante 20,30 y $45 \mathrm{~min}$. a $50^{\circ} \mathrm{C}$; posteriormente se retiró el exceso de colorante y se agregaron $30 \mu 1$ de colorante diluido $1: 1$ con ácido acético glacial al 45\% durante $10 \mathrm{~min}$.

En el segundo caso se utilizó DAPI ó 4 '6-diamidino2-fenilindol es cual es un fluórocromo que se une fuertemente a ADN. Esta sustancia pasa a través la membrana celular, puede ser utilizada para teñir en vivo o en células fijadas el acido nucleído. Se agregaron $30 \mu 1$ de este reactivo sobre el tejido por $10 \mathrm{~min}$ a temperatura ambiente en condiciones de oscuridad para evitar el desgaste de ésteantes de ser visualizado.

Para el montaje se utilizaron dos técnicas; squash o aplastamiento y extendido; para lo cual se tomo el tejido que previamente había sido degradado por la hidrólisis y se extendió con una pinza de punta fina o una aguja a través de las $2 / 4$ partes centrales del portaobjetos y posteriormente se sometió al proceso de tinción con orceína acética o DAPI.

La observación se realizó en un microscopio óptico marca GS-VISION, inicialmente en el campo visual de
10X para buscar las áreas de la placa con mayor dispersión celular, luego se procedió al campo visual de $40 \mathrm{X}$ con el fin de seleccionar las células que presentaran una buena degradación de la pared celular, con un 80 al $100 \%$ de la membrana, que tuvieran su material genético condesando en cromosomas y presentaran una buena tinción; las cuales se observaban en detalle con el objetivo de $100 \mathrm{X}$ y se tomo registro fotográfico. Las laminas tincionadas con DAPI fueron procesadas en el microscopio de fluorescencia Labomed Lx400.

\section{RESULTADOS}

\section{Ciclo celular e índice mitótico}

Para la determinación del ciclo celular en G. angustifolia var. angustifolia se contaron en promedio en un ciclo de 24 horas de treinta y un mil seiscientas nueve (31609) células, de las cuales el 51,9\% se encontraron en interfase, y el 48,1\% en mitosis (Tabla 1).

Índice mitótico: Del porcentaje mencionado, el 44,5\% corresponde al tiempo de duración de la profase y el $3,6 \%$ restante a las demás fases mitóticas (Tabla 1 ). Por lo tanto, el Índice mitótico: para la especie es de 48,1\%.

Duración del ciclo celular: Para G. angustifolia Var. angustifolia el tejido meristemático tiene una duración de ciclo de cuatro horas con diez minutos (4:10'), de las cuales la mayor parte del tiempo está ocupada por la interfase con dos horas diez minutos $\left(2: 10^{\prime}\right)$, mientras que la mitosis tiene una duración de dos horas (2:00'); donde la fase más prolongada es la profase con una duración de una hora con cincuenta y cuatro minutos (1:54') (Tabla 1).

Hora mitótica: Se calculó el IM $m$ (índice mitótico), el cual evidenció un comportamiento bimodal. Dos horas

Tabla 1. Determinación de IF, IM totales y la duración del ciclo celular para G. angustifolia var. Angustifolia biotipo Macana.

\begin{tabular}{|c|c|c|c|c|c|c|}
\hline Estado & Total & Interfase & Profase & Metafase & Anafase & Telofase \\
\hline $\begin{array}{l}\text { Numero de } \\
\text { células }\end{array}$ & 31609 & 16310 & 14129 & 455 & 549 & 166 \\
\hline IF (\%) total & 100 & 51,59 & 44,69 & 1,4 & 1,7 & 0,5 \\
\hline IM (\%) & $48,148.3$ & \multicolumn{5}{|c|}{$(44,5+1,4+1,7+0,5)$} \\
\hline Duración total & 4,17 & 2,2 & 1,9 & 0.05928 & 0.07152 & 0.02106 \\
\hline $\begin{array}{l}\text { del ciclo en } \\
\text { horas. }\end{array}$ & $4: 10^{\prime}: 00^{\prime \prime}$ & $2: 10^{\prime}: 00^{\prime \prime}$ & $1: 54^{\prime}: 00 "$ & $0: 03^{\prime}: 06^{\prime \prime}$ & 0:04':02”' & 0:01':02"' \\
\hline
\end{tabular}


del día (9:00 am y 2:00 pm) fueron las de mayor actividad mitótica, la primera con un valor de 78,7\%, coincidiendo con el rango horario de mayor actividad mitótica para las especies vegetales; que se estima entre las 8 y las 10am, mientras que la segunda tuvo un valor del $83,5 \%$ al inicio de la tarde(2pm), que incluso es mayor que el encontrado en las horas de la mañana (Figura 1).

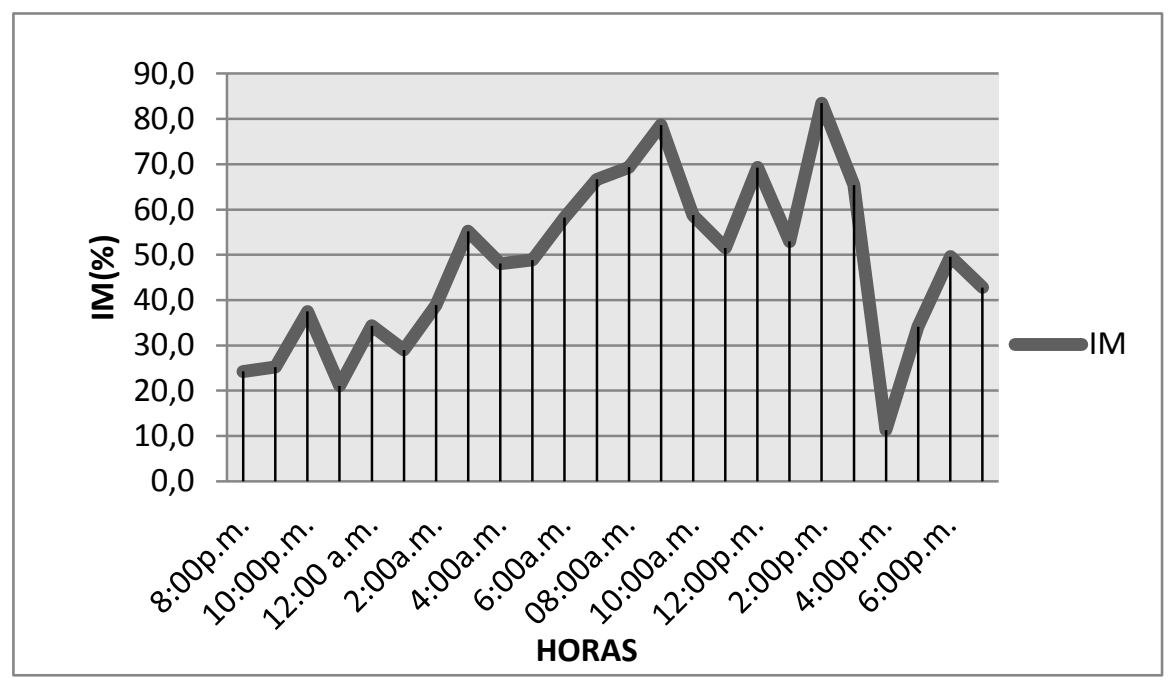

Figura 1. Secuencia del ciclo celular para G. angustifolia

Según lo observado en la interfase, el núcleo de las células de G. angustifolia var. angustifolia presentó una coloración homogénea (Figura 2a); en la profase temprana los cromosomas se hicieron visibles por primera vez con una apariencia de pequeños filamentos (Figura $2 \mathrm{~b}$ ), los cuales, a medida que avanzaba el proceso mitótico se transformaron en estructuras más gruesas, compactas y cortas, producto del proceso de condensación propio de esta fase (Figuras 2c). Ya en metafase los cromosomas se encontraron alargados y entrelazados en el plano ecuatorial Se logro un conteo de cromosomas? (Figura 2d); la anafase muestra la separación inicial del material genético sobre el plano ecuatorial (Figura 2e), mientras que se observó ésta en estado tardío, donde es evidente la migración del material genético hacia los polos (Figura 2f), en la telofase se puede notar el inicio de la formación de la pared celular que posteriormente conllevará a la citocinesis (Figura 2g).

\section{Estandarización del protocolo para la observación de cromosomas en metafase}

\section{Pretratamiento}

Para la estandarización se emplearon ápices radiculares colectados a las 9am. Los resultados para el pretratamiento físico a $0^{\circ} \mathrm{C}$ mostraron un bajo número de células en metafase (inferior al 20\%), mientras que la cantidad de células en estadío metafásico aumentó con el uso del agente químico colchicina siendo $2 \mathrm{~h}$. el tiem- po de exposición con mejores resultados $60 \%$ de células en metafase (Figura 3); un tiempo de exposición mayor puede inducir la poliploidización (13), condición que no es favorable en este estudio ya que no se conocía con certeza la dotación cromosómica de la especie y un tiempo menor no permite obtener una buena cantidad de células inhibidas, ya que la presencia de la pared celular, fosfolípidos y proteínas de membrana, limitan la penetración del inhibidor del huso mitótico.

\section{Fijación}

La evaluación de los diferentes tiempos de fijación se hizo de manera descriptiva sobre las variaciones en la morfología de los cromosomas, la persistencia de residuos citoplasmáticos y el estado de deshidratación de los tejidos, características que influyen en la resolución con la que se lograron visualizar los cromosomas.

Teniendo en cuenta los resultados, los tiempos de exposición menores a 12 horas no permitieron una adecuada visualización de la estructura cromosómica, por la permanencia de restos citoplasmáticos, se estimó que la exposición al fijador para la especie debe ser como mínimo de 24 horas para conseguir distinguir cromosomas adecuadamente.

\section{Hidrólisis}

La hidrólisis ácida presentó buenos resultados para la degradación de la pared al emplearse una concentración $2 \mathrm{~N}$ durante 20 minutos a $50^{\circ} \mathrm{C}$, sin embargo, persistie- 


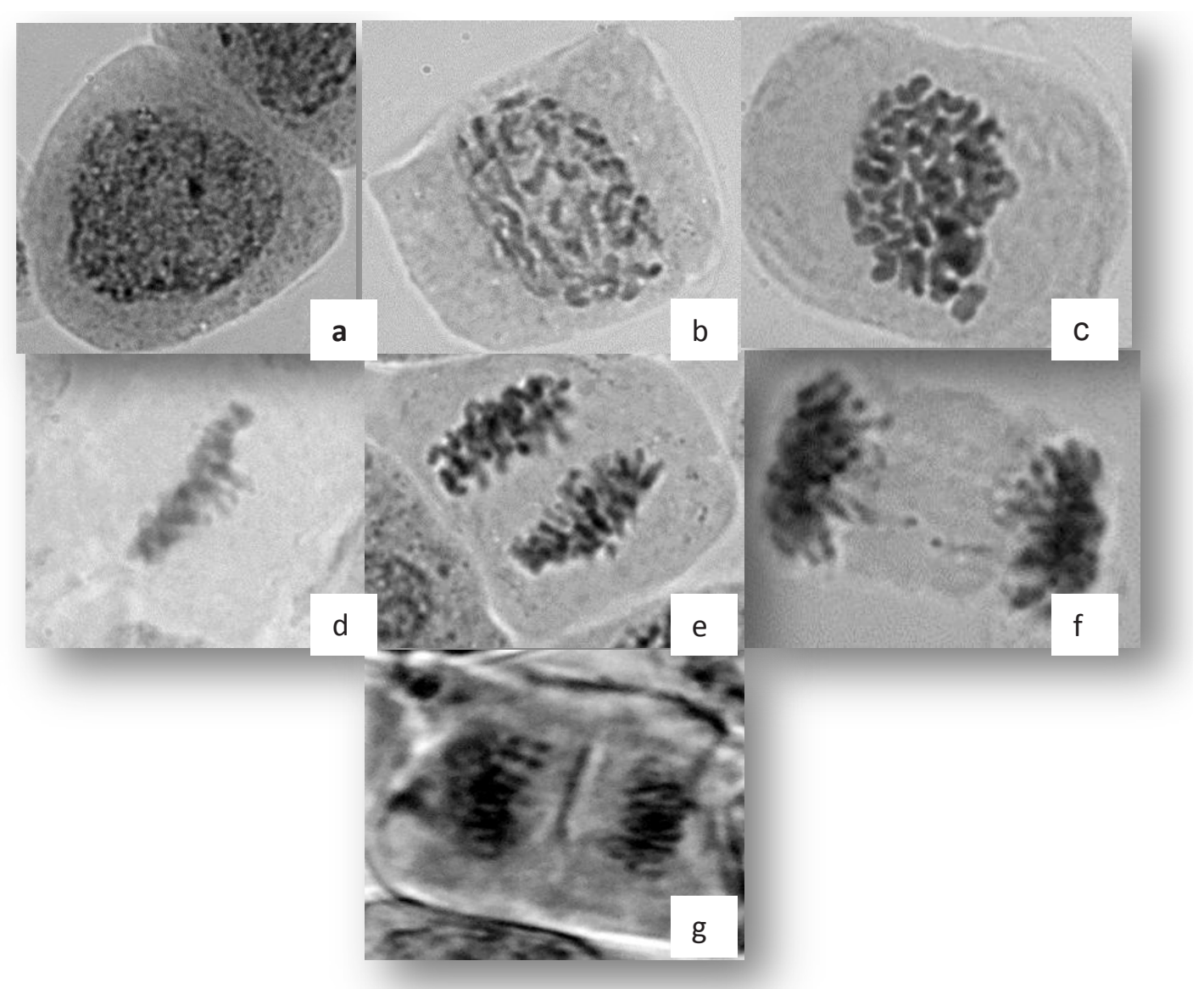

Figura 2. Células de G. angustifolia var. angustifolia a. interfase, b. profase temprana, c. profase tardía, d. metafase e. anafase temprana, f. anafase tardía, g. telofase.

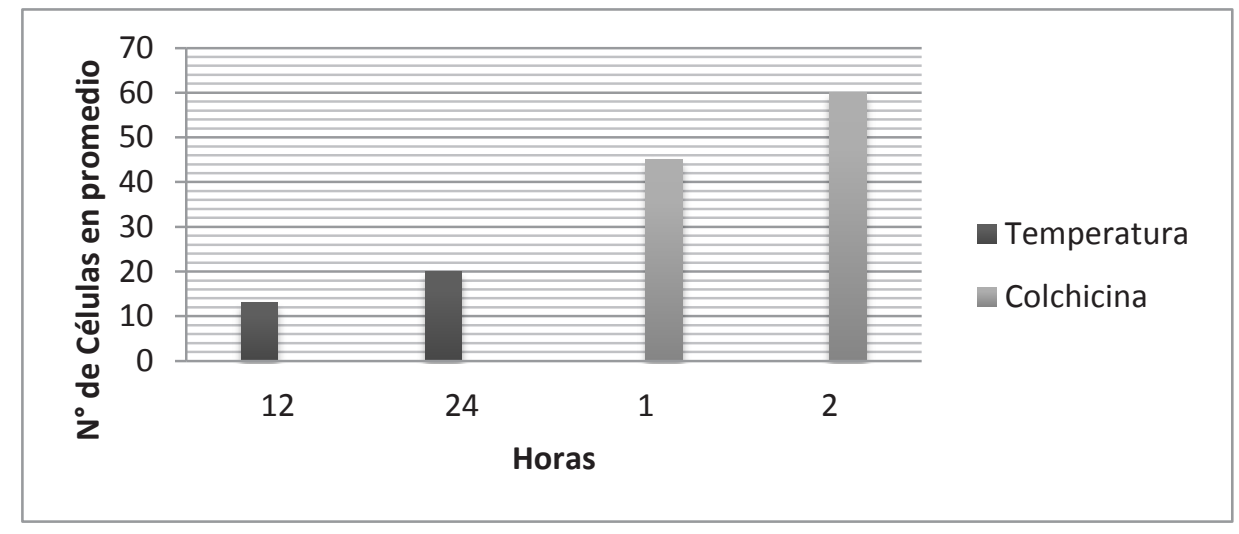

Figura 2. Promedio de 1000 metafases de G. angustifolia var. angustifolia acumuladas con los pretratamientos utilizados. 
ron restos de pared que impidieron obtener montajes de cromosomas en un solo plano, concentraciones iguales o menores y tiempos de exposición más bajos, no permitieron retirar la pared; mientras que una concentración mayor $(3 \mathrm{~N})$ fue un tratamiento drástico, con el cual se observó un daño celular donde se perdió completamente la morfología de las células, obteniendo preparaciones de aspecto amorfo, sin células ni cromosomas reconocibles. La combinación de la hidrólisis acida con la enzimática permitió la degradación de la pared celular y la adecuada visualización de $\operatorname{los} 2 \mathrm{n}=2 \mathrm{x}=46$ cromosomas.

\section{Tinción, montaje y observación}

Para la tinción y el montaje cromosómico, se siguieron las recomendaciones de García (14), antes de teñir el tejido se agregaron $30 \mu 1$ de ácido acético al $70 \%$ para que las células quedaran fijadas sobre el portaobjetos, posteriormente, se realizaron tres lavados con agua destilada estéril de cinco minutos cada uno con el fin retirar el exceso del reactivo.

La tinción con orceína acética permitió la observación de cromosomas bien coloreados después de 30 minutos, posteriormente se uso la técnica de squash para la dispersión del tejido; siendo adecuado para G. angustifolia var. angustifolia.

En cuanto a la tinción con DAPI se utilizó la técnica de extendido, con la que se obtuvo resultados óptimos debido a la especificidad de este fluórocromo por el ADN con altos grados de condensación (cromosomas). Para finalizar en ambos casos se colocó el cubreobjetos y se procedió a la evaluación visual de la placa en el microscopio con el objetivo 100X.

\section{DISCUSIÓN}

Los resultados con respecto a la duración del ciclo celular fueron coherentes con respecto a la duración de las fases del ciclo celular de la mayoría de las especies, debido a que la mitosis es un poco más corta que la interfase; que es el periodo donde la célula crece en volumen y efectúa funciones metabólicas, transcripción, traducción y duplicación, lo cual justifica que más de la mitad del ciclo celular sea invertido en tales actividades (15-17).

Kreps y Kay (18), proponen que factores ambientales como la luz, humedad y temperatura se encuentran estrechamente relacionados con las variaciones en los ciclos celulares, ya que, se comportan como factores interdependientes; de tal modo que la luz promueve la morfogénesis, crecimiento, desarrollo y es necesaria para la activación de la fotosíntesis. El efecto de la temperatura es directamente proporcional al desarrollo de la planta (producción de hojas, tallos y raíces); por tal motivo, las poblaciones celulares con que se trabajó pertenecen a un sistema asincrónico y explicarían el comportamiento bimodal de la actividad mitótica.

Las mediciones de los diferentes parámetros de la actividad celular en poblaciones asincrónicas darán solo valores promedio, como los que se presentan en este trabajo; ya que tales parámetros, variaron en todas las células según en el momento del ciclo que se encontraba la célula y las condiciones ambientales que se presentaban (19).

El índice mitótico de G. angustifolia var. angustifolia mostró un crecimiento en el número de células que se encuentran en el estadío de mitosis, relacionado con el fotoperiodo, ya que éste varió a través de las 24 horas del día mostrando altibajos, indicando que la división celular para esta especie es altamente influenciada por los ciclos de luz y oscuridad (20).

La división celular aumentó en las horas de mayor intensidad lumínica, ya que se incrementan las concentraciones de carbohidratos producidos por el metabolismo de la planta; por tanto, es de esperarse que los cambios de fase, dentro del ciclo celular, se hicieran dentro de este periodo de tiempo, debido a que estas actividades demandan un gasto alto de ATP, por ejemplo, el cambio de ADN relajado como se encuentra en la interfase y la fase de síntesis requiere de un gasto energético por parte de la planta (21), e igualmente esto ocurre en los mecanismos de regulación del ciclo celular que implican el ingreso de la célula a la mitosis.

El momento del día en el cual las células entran en el proceso de mitosis varía de una especie a otra; por lo general, va desde las 7 am hasta aproximadamente las 11:00 am, con un óptimo entre las 9 y 10 am $(22,23)$, esto coincide con lo encontrado en este trabajo, pero, cabe resaltar que G. angustifolia var. angustifolia presenta un comportamiento bimodal, y que a las 2:00 pm hay un aumento notable en la actividad mitótica que puede relacionarse con que las poblaciones celulares exhiben oscilaciones mitóticas, crecimientos periódicos o bien una mezcla de ciclos de crecimiento lento y rápido (24-27). 
La profase en la especie, se caracterizó por un alto número de células hacia las 3:00 am; sin embargo, el valor máximo se encontró hacia las $10 \mathrm{am}$. Según lo expuesto por Ekamen y Osuji (28), los niveles de mitosis observados tienen un punto máximo cuando hay luz solar, lo que indica que estos procesos demandan para la planta altas cantidades de ATP.

La duración del ciclo celular fue de 04:10', tiempo que es considerado corto según Talledo y Escobar (9). Esto se relaciona con la eficacia metabólica de G. angustifolia var. Angustifolia por presentar fotosíntesis tipo $\mathrm{C}_{4}$ $(1,29)$, dado que ésta es más eficiente en la captura de $\mathrm{CO}_{2}$; poseen una tasa máxima de crecimiento $40-50 \mathrm{~g} /$ $\mathrm{m}^{2} \mathrm{~d}$ y una productividad entre 70 y 80 ton/año, que en ambos casos, es superior a las tipo $\mathrm{C}_{3}$ y CAM (30).

La duración de ciclo celular de esta especie es corto, para ser de tipo forestal perenne; hay reportes de otras especies vegetales anuales tales como Phaseolus acutifolius, Ph. aureos, Ph. coccineus, Ph. lunatus donde la duración en promedio es 10:00 horas; para Zea mays es igual a 11:30', en el caso del género Ullucus el valor es 6:20' (9) mientras en especies como Iresine herbstii la duración es de 24:00'06" y en I. retusifolia dura 23:24'02" (31).

En síntesis, el hallar un ciclo celular corto en la Guadua explica el rápido crecimiento y capacidad colonizadora, porque las células entran en mitosis más de una vez en el día, lo cual permite la rápida proliferación de tejidos, justificándose la observación del comportamiento bimodal en la actividad mitótica (9:00 am y 2:00 pm).

\section{Estandarización del protocolo para la observación de cromosomas en metafase.}

\section{Pretratamiento}

El pretratamiento físico con baja temperatura $\left(0^{\circ} \mathrm{C}\right)$ actúa sobre toda la célula deteniendo bruscamente los procesos vitales que se estén llevado a cabo, sin ser especifico $(12,13)$; sin embargo, este método ha sido efectivo en plantas de tipo herbáceo y con cromosomas pequeños, donde se utilizan largos tiempos de exposición que pueden llegar a generar un acortamiento considerable en la longitud de los cromosomas (17); teniendo en cuenta lo anterior, la poca efectividad obtenida en este trabajo se relaciona con el hecho de que la especie sea de tipo leñoso.

De acuerdo a los resultados obtenidos (Figura 3), el ma- yor número de metafases acumuladas se logró mediante el uso de colchicina, ya que es un agente químico que actúa directamente interfiriendo en la división celular, por medio de la disociación de las subunidades $\alpha$ y $\beta$-tubulina que componen los microtubúlos (32).

\section{Fijación}

A medida que aumentó el número de horas, el fijador actuó sobre los componentes citoplasmáticos deshidratando homogéneamente la célula. Un tiempo prolongado superior a las 24 horas alteró la morfología cromosómica afectando sensiblemente la visualización de los cromosomas, En especies como Physalis peruviana L. (33) Rubus glaucus (34), Iresine herbstii e I. retusifolia (31), utilizaron tiempos de fijación de 24 horas eliminando los residuos citoplasmáticos y permitiendo extendidos adecuados para estudios de citogenética, lo que concuerda con lo obtenido en este estudio.

Según lo propuesto por Fukui y Nakayama (12) y los resultados del presente estudio, se considera adecuado poner los ápices colectados después de 24 horas de fijación en etanol al 70\%, para evitar el endurecimiento excesivo y la deshidratación total o parcial del tejido.

\section{Hidrólisis}

Según lo recomendado por Moscone (35), Hernández (36) y Guerra y Souza (37) el empleo de cocteles enzimáticos arrojó los resultados esperados, las concentraciones de celulasa $(3.6 \%)$, pectinasa $(6 \%)$ y macerozima $(0.4 \%)$ durante 120 minutos, degradó parte de la pared celular permitiendo observar extendidos cromosómicos. Mientras que hidrólisis realizadas con bajas concentraciones de enzimas y tiempos de exposición inferiores a 120 minutos no degradaron la pared evitando la visualización de los cromosomas en un solo plano.

De acuerdo con los resultados obtenidos se encontró que una hidrólisis ácida tradicional con $\mathrm{HCl}$ al $1 \mathrm{~N}$ a $60^{\circ} \mathrm{C}$ en un intervalo de tiempo de 5 a 15 minutos, no fue suficiente para la especie, debido a que las gramíneas por lo general poseen raíces duras y en el caso de las especies de tipo forestal como la guadua, con alta concentración de ligninas (37) hace que esta fase deba de ser más agresiva, dada la naturaleza de sus fibras que le dan resistencia a factores fisicoquímicos que dificultan el deterioro de la pared celular, por lo tanto la hidrólisis ácida que arrojo los mejores resultados para estudios citogenéticos fue de 20 minutos con HCL al $2 \mathrm{~N}$ a $50^{\circ} \mathrm{C}$, reforzada con el coctel enzimático de celulasa al 3.6\%, Pectinasa al 6\% y Macerozima al 0.4\% 
durante 120 minutos a $37^{\circ} \mathrm{C}$., Por lo tanto, como la pared celular está compuesta por fibras de celulosa en una matriz de lignina y hemicelulosa, es necesaria la doble hidrólisis, con concentraciones altas tanto de ácido clorhídrico como del coctel enzimático, agregando a éste macerozima, que tiene como función degradar la hemicelulosa, para lograr retirar la pared celular y así liberar el material genético condensado en cromosomas. La doble digestión; primero ácida, para debilitar la pared celular y la enzimática para terminar de degradar sus componentes, es sin duda, una combinación ideal para obtener preparaciones de buena calidad como se encontró en los reportes para Rubus glaucus (34), Iresine herbstii e I. retusifolia (31), Physalis peruviana L (33) y Coffea arabica L. (38), dado que garantiza la desestabilización de la composición de la pared celular hasta lograr el rompimiento de la célula, lo que permitió que el material genético condensado en cromosomas quedará disperso y apto para su estudio.

\section{Tinción, montaje y observación}

Las sustancias que son utilizadas como tintes se disuelven en agua en forma de iones coloreados, enlazándose química y físicamente a las proteínas sin perder su color (11). Por ejemplo, la orceína acética es un colorante básico, y por lo tanto tiene afinidad por los componentes ácidos, como el DNA, por lo tanto fue un colorante adecuado para la observación de los cromosomas en la especie G. angustifolia Var. angustifolia. Sin embargo, se lograron mejores resultados con la utilización de DAPI, ya que, se obtuvieron imágenes más adecuadas para el conteo y descripción morfológica de los cromosomas relacionándose con la especificidad que el fluórocromo posee por la cromatina y su visualización en un microscopio de fluorescencia.

\section{CONCLUSION}

La determinación del ciclo celular y la estandarización de las técnicas apropiadas para lograr cromosomas de buena calidad son fundamentales en estudios de cariotipificación, ya que de estas dependerá el logro de buenos resultados y el nivel de repetitividad en los diferentes laboratorios, gracias a los resultados obtenidos se logro estandarizar la técnica para la visualización de los cromosomas metafásicos de las células meristemáticas de Guadua angustifolia Var. angustifolia, para lo cual fue vital establecer la duración del ciclo celular (04:10') y determinar el índice mitótico que para esta especie presenta los valores más altos entre a las 9:00 am y 2:00 pm, horas en las cuales se colectaron los ápices radi- culares para estandarizar posteriormente la técnica empleando colchicina $1 \%$ por $2 \mathrm{H}$ a $\mathrm{T}^{\circ}$ ambiente, fijación con Carnoy con un mínimo 24 horas, doble hidrólisis: $\mathrm{HCl}$ al $2 \mathrm{~N} 20 \mathrm{~min}$ a $50^{\circ} \mathrm{C}$ y coctel enzimático de celulosa al $3.6 \%$ pectinasa $6 \%$ y macerozima al $0.4 \%$ a $37^{\circ} \mathrm{C}$, finalmente tinción con orceína-acética o DAPI. Lo anterior permitio establecer para la especie una dotación $2 n=2 x=46$. 


\section{BIBLIOGRAFÍA}

1. Cruz H. Bambú - Guadua, Guadua angustifolia Kunt.- Bosques Naturales en Colombia y plantaciones comerciales en México. Primera edición. Grafica olímpicas S.A. 2009. 49p

2. Marulanda M., López A. y Claroz J. Analyzing the genetic diversity of Guadua spp. In Colombia using rice and sugarcane microsatellites. In: Crop Breeeding and Applied Biotechnology. Brazilian Society of Plant Breeding. 2007; (7): 43-51.

3. Pérez - Flórez A M. Guadua angustifolia Kunth. 1822. Tomado del sitio http://www.siac.net.co/sib/ catalogoespecies/especie.do?idBuscar=280ymethod=dis. Julio 16 de 2010.

4. Judziewicz EJ., Clark L G., Londoño X., Stern M. American Bamboos. Smithsonian Institution Press. Washington. 1999; $392 \mathrm{p}$.

5. Marulanda M., Carvajalino M., Vargas C., y Londoño X. La Biotecnología Aplicada al Estudio y Aprovechamiento de la Guadua. Memorias del seminario taller avances en la investigación sobre Guadua. Pereira-Colombia. 2002. 56p

6. Castaño F. Definición Técnica de un Régimen de Aprovechamiento de Bosques de Guadua (Guadua angustifolia Kunth) y su Incidencia en la Sostenibilidad, Sanidad y Rentabilidad del Recurso. Experiencias en el Departamento del Valle del Cauca, Colombia. Memorias del seminario taller avances en la investigación sobre Guadua. Pereira-Colombia. 2002.

7. Riaño N., Londoño X., López H., y Gómez J. Plant growth and biomass distribution on Guadua angustifolia Kunth in relation to ageing in the Valle del Cauca - Colombia. The Journal of the American Bamboo Society. 2002; 16(1): 43-51.

8. Bandini, R. Filogeografia, diferenciaçāo geográfica e caracterizaçāo citogenética de populaçōes naturais de Psychotria ipecacuana das florestas atlántica e amazŏnica. Viçosia - Minas Gerais; Tese apresentada do titulo do Doctor Scientiae a Universidade Federal de Vicosa. Brasil. 2007.

9. Talledo D y Escobar C. El ciclo celular en vegetales: su estudio, importancia y aplicaciones. Revista Biotempo. 1995; 2: (13) 20-31.

10. García, A. Manual de técnicas citogenéticas. Editorial colegio de postgrados. Chapingo México. 1977. 32p

11. Sharma K y Sharma A. Chromosome techniques, Theory and practice. 3ra edition. Butterworths \& Co. London. 1980.312p

12. Fukui y Nakayama. Plant Chromosomes. Laboratory Methods. CRC Press Inc. New York.. 1996.274p

13. Jahier J. Techniques of plants cytogenetics. Editorial Science Publisher. Estados Unidos de América. 1996. 89p

14. Garcia A. Manual de técnicas citogenéticas II. Editorial colegio de postgrados. Chapingo México. 1980. $45 p$

15. Karp G. Biología celular y molecular. Cap. 14 "Reproducción Celular". Editorial McGraw Hill Internacional. 1998; 580-616p.

16. Matos A y Molina J. Estúdio citogenético de células radicales de Aloe vera L. Revista Agronomía Colombiana. 1997; 14:173-182.

17. Singh R. Plant Cytogenetic. Chapter 6. Karyotype analysis. Editorial CRC press. Second edition. 2003; 113-123p.

18. Kreps J y Kay S. Cordination of plant metabolism and development by the circadian clock. The Plant Cell. 1997; 9:1235-1244.

19. Roca M y Mroginski A. Cultivo de Tejidos en la Agricultura, Fundamentos y Aplicaciones. Ed. Centro Internacional de Agricultura Tropical, Colombia. 1993. 2651p

20. Halaban R. Mitotic index and cell cycle of Lemma perpusilla under different photoperiods. Plant Physiology. 1972; 50: 308-310.

21. Van't Hof J. Control of cell progression through the mitotic cycle by carbohydrate provision. Cell Biology, 1968; 37: 773-780.

22. Ackeman W. Genetic and cytological studies whith camellias and related genera. Agricultural Research Service U.S.D.A Technical, 1971; 142 (7): 79-83. 
23. Swanson C., Merz T., y Yuong W. The chromosome in division, inheritance and evolution. Segunda edición. Prentice Hall, INC., Englewood Cliffs. New Jersey. U.S.A. 1981; 304 p.

24. Everett N., Wang T., Gould A., y Street H. Studies on the control of the cell cycle in cultured plants cell. II. Effects of 2,4 dichlorophenoxyacetic acid (2,4-D). In: Protoplasma. 1981; 106: 15-22.

25. Wang T., Everett N., Gould A., y Street H. Studies on the control of the cell cycle in cultured plant cells. III. The effects of cytokinin. In: Protoplasma. 1981; 106: 23-25.

26. Gould A y King P., Control of the cell cycle in cultured plants cell. CRC. Crit. Revista. Plant Science. 1984; 1(4):315-344.

27. Osuji J y Owei S. Mitotic index studies on Treculia africana Decne, in Nigeria. In: Australian Journal of Agricultural Engineering. 2010; 1(1): 25-28.

28. Ekamen A y Osuji J. Mitotic index studies on Edible cocoyams (xanthosoma and colocasia spp). In: African Journal of Biotechnology. 2006 ; 5(10): 846-849.

29. Cruz H. La Guadua nuestro bambú. Corporación autónoma regional del Quindío - centro nacional para el estudio del bambú Guadua. 1994; 34 - 121p.

30. Leegood, R.C. Carbon Dioxide Concentrating Mechanisms. P.J. Lea and R.C. Leegood (Eds.). In: Plant Biochemistry and Molecular Biology. John Wiley and Sons, Ltd. Chichester, U.K. 1993.p

31. Pantoja J. Estudio citogenético de Iresine herbstii Hook e Iresine retusifolia Agudelo (Amaranthaceae) de Colombia. Armenia, Universidad del Quindío. Facultad de Ciencias Básicas y Tecnologías. Tesis de pregrado. Programa de Biología. 2010.

32. Taylor E. The mechanism of colchicine inhibition of mitosis, I. kinectics of inhibition and the binding of $\mathrm{H}^{3}$ - colchicines. In: Cell Biology, 1965; 25: 145-160.

33. Rodríguez N y Bueno A. Estudio de la diversidad citogenética de Physalis peruviana L. (Solanaceae). En: Acta Biológica Colombiana. 2006; 11 (2): 33-43.

34. Delgado L. Estandarización de la técnica citogenética con ápices radiculares para el conteo de cromosomas mitóticos en Rubus glaucus Benth. Armenia. Universidad del Quindío Facultad de Ciencias Básicas y Tecnologías . Tesis de pregrado. Programa de Biología. 2009.

35. Moscone E. Chromosome studies on Capsicum (Solanaceae) L. Karyotype analysis in chacoense. In: Brittonia 1990; 42 (2): 147-154.

36. Hernandez M. Manual de Laboratorio “citología y citogenética”. Editorial Trillas, S.A. de C.V. 1990; $101 \mathrm{p}$.

37. Guerra M y Souza M. Como observar cromossomos: um guía de técnicas em citogenética vegetal, animal e humana. Editora FUNPEC. 2002; 34-43p.

37. Herrera J y Camayo G. Caracterización Morfológica y Citológica de Arboles de Coffea arabiga L., Regenerados por Cultivo in vitro de Polen Aislado. Revista Cenicafe. 2008; 59 (2): 143-154. 